\title{
SNAPSHOT
}

\section{Rivers of ice}

This detailed map was put together by ice-sheet modeller Eric Rignot, of the University of California, Irvine, and his colleagues who stitched together more than 3,000 orbits-worth of satellite data. Together, these reveal a picture of fast-flowing ice that "redefines our understanding of ice-sheet dynamics," the team writes (Science 333, 1427-1430; 2011). And they highlight some 'rivers' that no one has previously seen. "From about $80^{\circ} \mathrm{S}$ to the South Pole there are lots of areas where there were no data before," says Rignot.

Previously, most continent-wide estimates of surface ice flow have been made by models that use the ice thickness, surface slope and snow accumulation rates to estimate flows. But that method involves assumptions and simplifications that don't always hold true.

Satellite radar interferometry (InSAR) provides a much more accurate way to measure what's really happening on the ground: radar is used to spot surface features and track how they move over repeated satellite passes. Rignot's team gathered data from the Canadian RADARSAT, the European Envisat and the Japanese Advanced Land Observing Satellite, and filled in patches using data from a few other satellites, from 2007 to 2009

The detected ice-flow speeds ranged from a few centimetres per year to a few

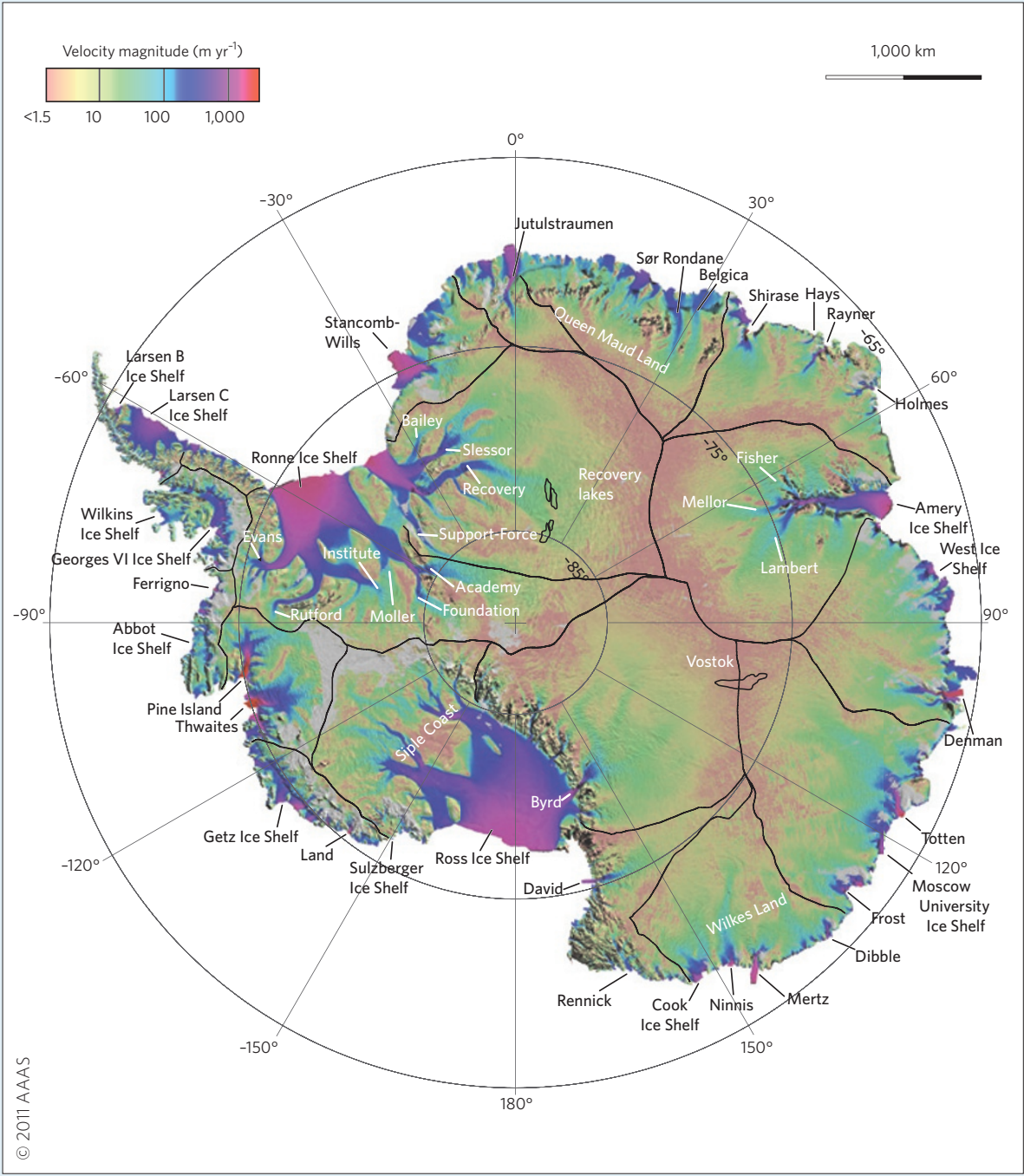

kilometres per year. Unsurprisingly, the fastest ones were Pine Island and Thwaites, which have been accelerating in recent years, triggering worries about dramatic sea-level rise.

The work highlights the fact that the main force driving these glaciers isn't always the deformation of ice from the pressure of its own weight - glacier speeds can be hundreds of times faster than implied from that mechanism alone, Rignot explains. Instead, the main driver is the slipping of glaciers along a melted layer at their base - not just at the coast but throughout the continent. "We didn't expect to see that so far inland," says Rignot.

Their ice-flow-speed results match those predicted by models in areas where the ice is moving slowly, such as near ice divides. However, there are large differences in speed for some fast-moving ice basins and along the coast, compared with the models. There were also a few places where the flow location was not where the models predicted it would be. In Queen Maud Land - the Norweigan territory of Antarctica - the main trunk of the Jutulstraumen glacier flows not through a southern trough, as suspected, but to the east, for example. Unlike water rivers, the ice flows don't necessarily begin where there are sub-glacial lakes, and they don't necessarily follow the deepest troughs on the continent's buried rocky floor. "The flow often does follow big trenches, but it's not the general rule," says Rignot. "In some places you couldn't predict it from the shape of the bedrock."

The map will be useful for researchers aiming to study glacier movements in detail. "If you want to study ice flow in the interior, you wouldn't have known where to go before. With this tool in hand, you can refine a survey plan," says Rignot. He says scientists have already contacted him to check their research plans against the new map. It will also be useful for researchers wanting to set up semi-permanent monitoring stations or refuelling areas, to help ensure that these won't move too much over time. 